\title{
Mixed-Alkali Effect in Borate Glasses: Thermal, Elastic, and Vibrational Properties
}

\author{
Seiji Kojima®
}

Division of Materials Science, University of Tsukuba, Tsukuba, Ibaraki 305-8573, Japan;

kojima@ims.tsukuba.ac.jp; Tel.: +81-29-874-7728

Received: 29 September 2020; Accepted: 16 November 2020; Published: 19 November 2020

\begin{abstract}
When oxide glasses are modified by dissimilar alkali ions, a maximum in the electric resistivity or the expansion coefficient appears, called the mixed-alkali effect (MAE). This paper reviews the MAE on the thermal, elastic, and vibrational properties of the mixed-cesium lithium borate glasses, $x\left\{(1-y) \mathrm{Cs}_{2} \mathrm{O}-y \mathrm{Li}_{2} \mathrm{O}\right\}-(1-x) \mathrm{B}_{2} \mathrm{O}_{3}$. For the single-alkali borate glasses, $x \mathrm{M}_{2} \mathrm{O}(1-x)-\mathrm{B}_{2} \mathrm{O}_{3}(\mathrm{M}=\mathrm{Li}, \mathrm{Na}, \mathrm{K}$, $\mathrm{Rb}$, and $\mathrm{Cs}$ ), the glass transition temperature, $T_{\mathrm{g}}=270{ }^{\circ} \mathrm{C}$, of a borate glass monotonically increases as the alkali content $x$ increases. However, for the mixed-cesium lithium borate glasses the $T_{\mathrm{g}}$ shows the minimum against the lithium fraction $y$. The dependences of the elastic properties on the lithium fraction $y$ were discussed regarding the longitudinal modulus, Poisson's ratio, and Cauchy-type relation. The internal vibrational bands related to the boron-oxide structural groups and the splitting of a boson peak were discussed based on Raman scattering spectroscopy. The MAE on various physical properties are discussed on the basis of the changes in the coordination number of the borons and the nonbridging oxygens caused by the dissimilar alkali ions.
\end{abstract}

Keywords: mixed-alkali effect; borate glass; coordination number; elastic constants; boson peak

\section{Borate Glass and Alkali Modification}

Crystals and crystalline materials have a three-dimensional periodic structure with translational and point symmetries, therefore, their physical properties are anisotropic. Glasses and amorphous materials have a random structure with no translational symmetry and no point symmetry, therefore their macroscopic physical properties are isotropic. A glass is formed through a liquid-glass transition by rapid cooling from a supercooled liquid state into a nonequilibrium glassy state. Various kinds of organic and inorganic glasses are known among polymers, drugs, minerals, metals, semiconductors, etc. Among the inorganic glasses, oxide network glasses such as $\mathrm{SiO}_{2}, \mathrm{~B}_{2} \mathrm{O}_{3}$, and $\mathrm{P}_{2} \mathrm{O}_{3}$, have attracted much attention for their widespread practical applications by the combination of hardness and transparency at room temperature. The network structure of oxide glasses is remarkably modified by alkali ions, and such a modification has been used to control the various physical properties of glasses such as the glass transition temperatures, elastic properties, etc.

Borate glass $\left(\mathrm{B}_{2} \mathrm{O}_{3}\right)$ is one of the typical covalent network glasses. The network structure of the borate glass is formed by randomly connected planar $\mathrm{BO}_{3}$ triangles and most of them form planar boroxol $\mathrm{B}_{3} \mathrm{O}_{6}$ rings [1]. Alkali metals remarkably modify the network structure of a borate glass, and the variation in the microscopic structure and related physical properties as a function of the alkali content has been extensively studied. The alkali ions in a borate glass induce the change of the boron coordination number of a boron atom from three to four and non-bridging oxygens are created as alkali content increases. Due to these changes of the covalent bonds in the network structure, various kinds of structural groups are formed such as pentaborate, dipentaborate, diborate, triborate, metabolite, etc., depending the alkali metals and their contents [2,3]. A rich variation of the structural units causes remarkable changes in the various physical properties. For example, the Poisson's ratio of cesium 
borate glasses shows a minima and maxima with the increasing cesium content [4]. Such non-linear variations in the various physical quantities versus the alkali contents are called a "borate anomaly".

The medium range order (MRO) is the arrangement of the structural units, which controls various physical properties such as the elastic constants and density. The MRO is estimated by the first sharp diffraction peak (FSDP) in the static structure factor, $\mathrm{S}(\mathrm{Q})$, measured by the neutron and X-ray diffraction experiments. The peak width $\Delta \mathrm{Q}_{\mathrm{fsdp}}$ of FSDP corresponds to a structural correlation length of $L_{\mathrm{fsdp}}=2 \pi / \Delta \mathrm{Q}_{\mathrm{fsdp}}$, which defines the MRO. The peak value $\mathrm{Q}_{\mathrm{fsdp}}$ corresponds to the real-space ordering with a periodicity of $2 \pi / \mathrm{Q}_{\mathrm{fsdp}}$ [5]. Figure 1a shows the static structure factor $\mathrm{S}(\mathrm{Q})$ of the single-alkali borate glasses, $0.22 \mathrm{M}_{2} \mathrm{O}-0.78 \mathrm{~B}_{2} \mathrm{O}_{3}(\mathrm{M}=\mathrm{Li}, \mathrm{Na}, \mathrm{K}, \mathrm{Rb}$, and $\mathrm{Cs}$ ) measured by neutron scattering [6]. The FSDP and the second peak are denoted by $Q_{1}$ and $Q_{2}$, respectively, in Figure 1 a. The MRO correlation length $L_{\mathrm{fsdp}}=2 \pi / \Delta \mathrm{Q}_{\mathrm{fsdp}}$ was determined from the width of a peak at $\mathrm{Q}_{1}$, i.e., $\Delta \mathrm{Q}_{1}$. The correlation between $L_{\mathrm{fsdp}}$ and the ionic radius $\mathrm{R}_{\mathrm{ion}}$ [7] is shown in Figure $1 \mathrm{~b}$. For the larger alkali ions, $L_{\mathrm{fsdp}}$ is nearly proportional to $R_{\mathrm{ion}}$. This relation indicates that a larger alkali ion occupies a void in the B-O network structure, while a smaller alkali ion $\mathrm{M}^{+}$locates near a $\mathrm{BO}_{4}^{-}$tetrahedron.

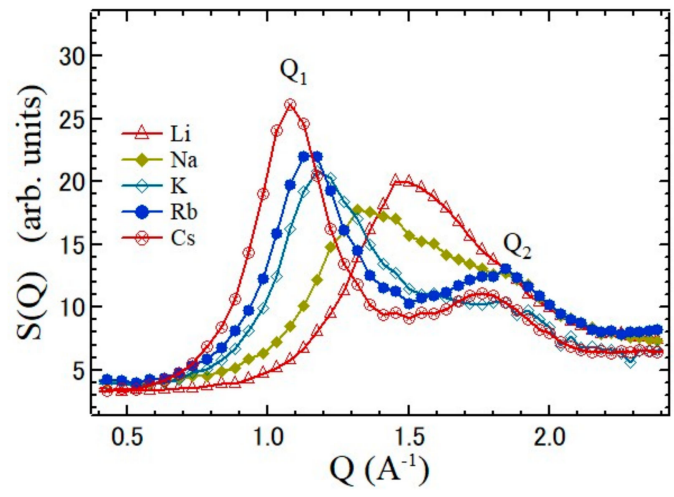

(a)

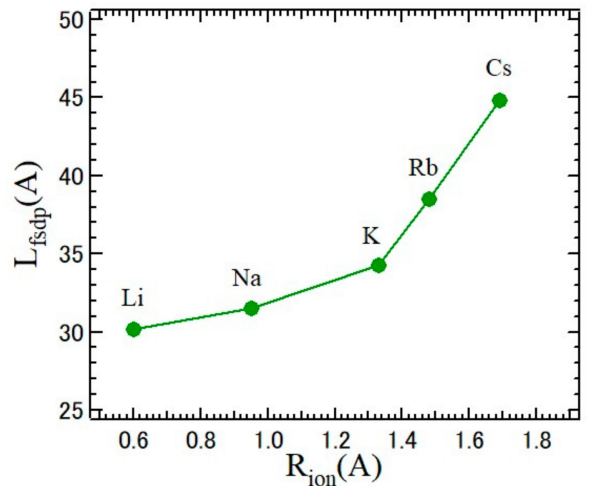

(b)

Figure 1. (a) Static structure factor, $\mathrm{S}(\mathrm{Q})$; (b) medium range order correlation length, $\mathrm{L}_{\mathrm{fsdp}}$ determined from the width of FSDP, $\Delta \mathrm{Q} 1$ of the single-alkali borate glasses, $0.22 \mathrm{M}_{2} \mathrm{O}-0.78 \mathrm{~B}_{2} \mathrm{O}_{3}(\mathrm{M}=\mathrm{Li}, \mathrm{Na}, \mathrm{K}, \mathrm{Rb}$, Cs) [6].

According to the study of the packing in alkali modified oxide glasses by Giri et al., ionic and covalent packings were discussed in terms of the relative volumes of the modified alkali cations compared to that of the networking forming oxygen [8]. For modifying alkali ions ( $\mathrm{K}, \mathrm{Rb}$, and $\mathrm{Cs})$ having an ionic radius larger than oxygen, the packing is dominated by the modifier alkali ions, and it is called ionic packing. Therefore, the linear relation between $L_{\mathrm{fsdp}}$ and the ionic radius $R_{\text {ion }}$ nearly holds for the larger alkali ions. For the alkali ions ( $\mathrm{Li}$ and $\mathrm{Na}$ ) having an ionic radius smaller than oxygen, the packing is controlled by the oxygen covalent network, and it is called covalent packing. For the smaller alkali ions, the linear relation between $L_{\mathrm{fsdp}}$ and the ionic radius $R_{\text {ion }}$ does not hold.

By modification of the oxide glasses by two dissimilar alkali ions, the maximum electric resistivity or the expansion coefficient were observed [9-12]. Such an anomalous variation is called the mixed-alkali effect (MAE) caused by the coexistence of two dissimilar alkali ions. For the various transport properties, such as the ionic conductivity and viscosity, a remarkable deviation from linearity was observed when one alkali cation substitutes for another at the totally fixed content of the alkali metals. In the MAE, interactions between dissimilar cations reduce their mobility, and remarkably affect the dynamic properties. Such interactions were thought to be associated with network-mediated "pairs" of dissimilar alkali ions, which are energetically favored relative to pairs of similar alkalis [13]. These non-linear behaviors are technologically important for developing low-loss electrical glasses. The non-transport physical properties, such as density, glass transition temperature, and elastic modulus, also reveal noticeable deviations from the linear variation of the alkali contents. However, the physical origins of the MAE on these non-transport properties are not yet clarified. 
This paper reviews the MAE of the borate glasses studied of the thermal analysis, neutron diffraction, ultrasonic method, Brillouin scattering, Raman scattering, and neutron inelastic scattering on the mixed-cesium lithium borate glasses, $x\left\{(1-y) \mathrm{Cs}_{2} \mathrm{O}-y \mathrm{Li}_{2} \mathrm{O}\right\}-(1-x) \mathrm{B}_{2} \mathrm{O}_{3}$. The glass transition temperature, heat capacity, elastic constants, internal Raman bands, and boson peaks show the deviation from the linear relation to lithium fraction. These various physical properties are discussed on the basis of the changes of coordination number of boron, creation of non-bridging oxygen, and dissimilar alkali ion pairs.

\section{Glass Transition Temperatures}

In various kinds of glasses, the liquid-glass transition temperature, $T_{\mathrm{g}}$, has been extensively studied. However, the understanding of the nature of the $T_{\mathrm{g}}$ is still not enough. Kauzmann suggested the empirical relation, $T_{\mathrm{g}} \sim 2 / 3 T_{\text {melt }}$, where $T_{\text {melt }}$ is the melting temperature [14]. Tanaka studied the correlation between the $T_{\mathrm{g}}$ and the average coordination number, $z$, per atom in covalent glasses. He found the empirical relation, $\ln T_{\mathrm{g}} \approx 1.6 \mathrm{~K} \times z+2.3 \mathrm{~K}$, and it holds well for chalcogenide glasses [15]. Although there have been many studies to understand the nature of the glass transition, and to relate $T_{\mathrm{g}}$ to the glass network connectivity, there is still no universal relationship satisfied by almost all kinds of glass formers [16].

The $T_{\mathrm{g}}$ of single-lithium and cesium borate glasses show remarkable alkali content dependences as shown in Figure 2a [4]. In the single-lithium borate glasses, the $T_{\mathrm{g}}$ monotonically increases as the $\mathrm{Li}$ content $x$ increases. In the single-cesium borate glasses, the $T_{\mathrm{g}}$ monotonically increases at first as the Cs content $x$ increases. The maximum of the $T_{\mathrm{g}}$ appears at about $x=0.28$, then decreases with a further increase in $x$. The difference in the alkali content dependences of the $T_{\mathrm{g}}$ between the lithium and cesium borate glasses is closely related to the difference in their network structures. Regarding the lithium borate glasses, Kerner discussed the relation between the $T_{\mathrm{g}}$ and the average coordination number of the glass former atoms [17]. However, the relation for other alkali borate glasses was not discussed.

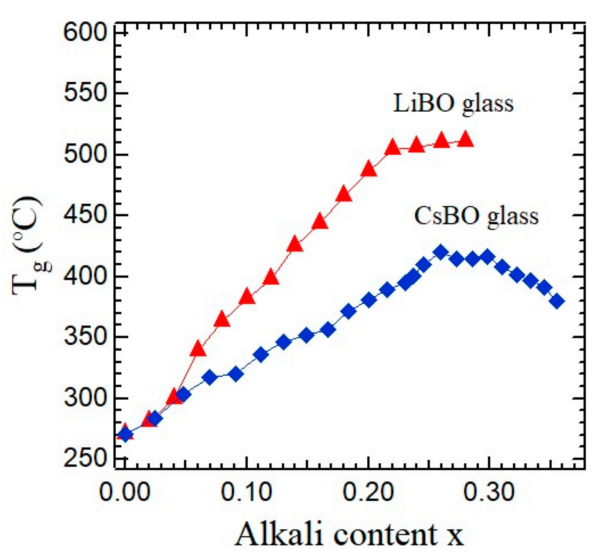

(a)

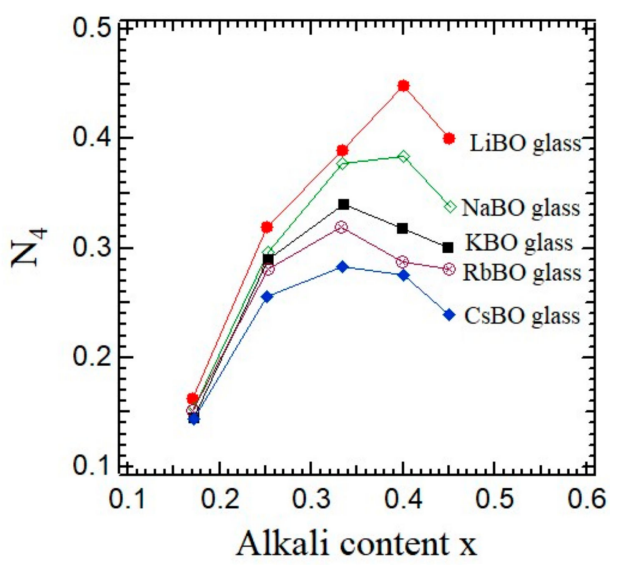

(b)

Figure 2. (a) Alkali content dependences of glass transition temperatures of lithium and cesium borate glasses [4]; (b) Alkali content dependences of $N_{4}$ of the single-alkali borate glasses, $x \mathrm{M}_{2} \mathrm{O}-(1-x) \mathrm{B}_{2} \mathrm{O}_{3}$ $(\mathrm{M}=\mathrm{Li}, \mathrm{Na}, \mathrm{K}, \mathrm{Rb}$, and $\mathrm{Cs})[18]$.

Zhong and Bray studied the alkali dependence of the number fractions of boron with three and four coordination numbers in the single-alkali borate glasses, $x \mathrm{M}_{2} \mathrm{O}-(1-x) \mathrm{B}_{2} \mathrm{O}_{3}(\mathrm{M}=\mathrm{Li}, \mathrm{Na}, \mathrm{K}, \mathrm{Rb}$, and Cs), using NMR [18]. The coordination number of boron in the pure borate glass is three, while by the alkali modification, it changes to four and non-bridging oxygens are created. The number fractions of boron atoms with three and four coordination numbers are denoted by $N_{3}$ and $N_{4}$, respectively, where $N_{3}+N_{4}=1$. In the single-alkali borate glasses, the correlation between the $T_{\mathrm{g}}$ and $N_{4}$ was reported as shown in Figure $2 \mathrm{~b}$ [18]. The variations of the $T_{\mathrm{g}}$ and $N_{4}$ versus the alkali content $x$ in Figure $2 \mathrm{a}, \mathrm{b}$ are qualitatively in agreement. The variation of $N_{4}$ on the alkali content presumably arises 
from the competition between the two processes [4]. One process is the formation of $\mathrm{B}_{4}{ }^{-}$units with 4-coordinated boron, where $\varnothing$ is a bridging oxygen and the positive alkali ion $\mathrm{M}^{+}$is adjacent to the negative $\mathrm{B}_{4}{ }^{-}$unit to keep the local charge neutrality. As the alkali ion size decreases, this process is enhanced. In the lithium borate glass, this process is more active than that in the cesium borate glass. Another process is the formation of a negative nonbridging oxygen $(\mathrm{NBO}), \mathrm{O}$, on a $\mathrm{B}_{2} \mathrm{O}^{-}$unit. The positive alkali ion $\mathrm{M}^{+}$is adjacent to the negative $\mathrm{O}^{-}$. As the alkali ion size increases, the negative Coulombic potential energy of the $\mathrm{B}-\varnothing-\mathrm{M}^{+}$configuration may decrease. In the cesium borate glass, this second process is more active than that in the lithium borate glass. Based on a comparison of plots of the lithium and cesium borate glasses between Figure 2a,b, the larger $N_{4}$ of the lithium borate glass is related to the higher $T_{\mathrm{g}}$ of the lithium borate glass. These results indicate that the first process of $N_{4}$ is more effective for the increase in the $T_{\mathrm{g}}$.

Next, we discuss the MAE on $T_{\mathrm{g}}$. A schematic illustration of a mixed-lithium cesium borate glass is shown in Figure 3. As discussed in Section 1. "Borate glass and alkali modification" using the FSDP of a static structure factor $\mathrm{S}(\mathrm{Q})$, a smaller $\mathrm{Li}^{+}$ion with the ionic radius of $0.60 \mathrm{~A}$ locates near the $\mathrm{B}$ atom, while a larger $\mathrm{Cs}^{+}$ion with the ionic radius of $1.69 \mathrm{~A}$ locates in a larger void of the B-O network. Zhong and Bray also studied the MAE on the $T_{\mathrm{g}}$ by NMR [18]. They found that the measured $N_{4}$ for the mixed-alkali borate glasses is less than the $N_{4}$ (average) value expected from a simple superposition calculated by the following equation:

$$
N_{4} \text { (average) }=0.5 N_{4}(\mathrm{Li})+0.5 N_{4} \text { (other alkali) }
$$

In some cases, $N_{4}$ (average) is even less than either of the $N_{4}$ values for the relevant single-alkali borate glasses. Ingram [19] made the following assumptions in an effort to explain the MAE: (1) in a mixed-alkali glass there is a preponderance of mixed-alkali pairs, e.g., $(\mathrm{LiK})^{2+}$ as compared to the alkali pairs, e.g., $(\mathrm{LiLi})^{2+}$; and (2) these mixed-alkali pairs are effectively immobilized.

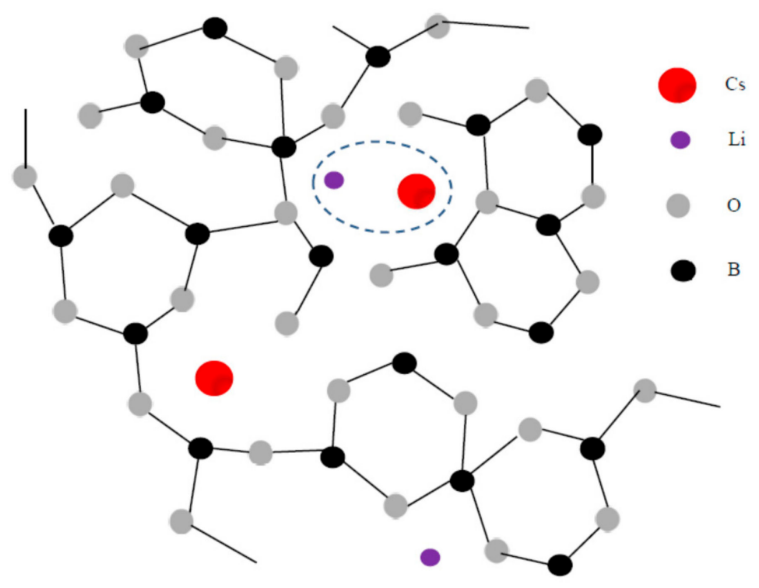

Figure 3. Schematic illustration of network structure of the mixed-cesium lithium borate glass. Near alkali ions, $\mathrm{B}_{4}{ }^{-}$and $\mathrm{B}_{2} \mathrm{O}^{-}$units are formed, where $\varnothing$ and $\mathrm{O}$ are the bridging and non-bridging oxygens, respectively. The appearance of dissimilar pair $(\mathrm{CsLi})^{2+}$ shown by dotted circle may cause the mixed alkali effect.

Figure 4 shows the Li fraction $y$ dependence of the $T_{\mathrm{g}}$ of the mixed-lithium cesium borate glasses, $0.28\left\{(1-y) \mathrm{Cs}_{2} \mathrm{O}-y \mathrm{Li}_{2} \mathrm{O}\right\}-0.72 \mathrm{~B}_{2} \mathrm{O}_{3}$. The solid line shows the linear relation. A negative deviation from the linear dependence is clearly observed. The minimum glass transition temperature at about $y=0.2$ was observed for the Li fraction $y$ dependence of a fixed alkali content. By using the molecular dynamic simulations, Vegiri et al. reported that the abundance of the $\mathrm{B}_{4}{ }^{-}$units decreases from the single-lithium to cesium glasses and exhibits a negative deviation from linearity in the mixed-cesium lithium glasses [13]. The existence of a minimum at about $y=0.2$ suggests a decrease in $N_{4}$ or an increase of the non-bridging oxygen around this fraction by the MAE. A similar minimum of 
the $T_{\mathrm{g}}$ for the constant alkali content was also reported in the mixed-cesium sodium borate glasses, $0.33\left\{(1-y) \mathrm{Cs}_{2} \mathrm{O}-y \mathrm{Na}_{2} \mathrm{O}\right\}-0.67 \mathrm{~B}_{2} \mathrm{O}_{3}$, and a correlation was shown between $T_{\mathrm{g}}$ and $N_{4}$ determined by the infrared absorption [20]. A molecular dynamics investigation of mixed-alkali borate glasses reported that the abundance of $\mathrm{B}_{4}{ }^{-}$units was found to decrease from $\mathrm{Li}$ to $\mathrm{Cs}$ and to exhibit a negative deviation from linearity in the mixed-cesium lithium borate glasses [13]. The dissimilar (CsLi) ${ }^{2+}$ pair may locate in a larger void, and it suppresses the formation of the $\mathrm{B}_{4}{ }^{-}$units. The existence of a dissimilar pair can be the origin of the minimum $T_{\mathrm{g}}$ at about $y=0.2$ in Figure 4 .

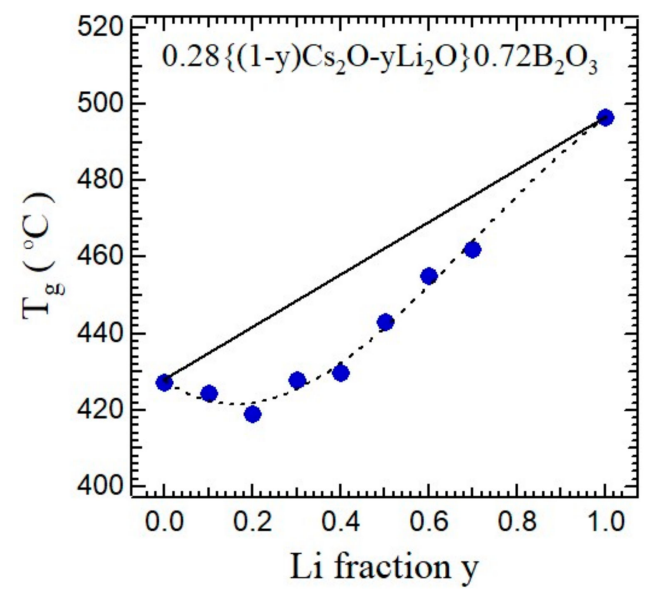

Figure 4. Li fraction $y$ dependence of glass transition temperatures in the mixed-cesium lithium borate glasses, $0.28\left\{(1-y) \mathrm{Cs}_{2} \mathrm{O}-y \mathrm{Li}_{2} \mathrm{O}\right\}-0.72 \mathrm{~B}_{2} \mathrm{O}_{3}[21]$.

\section{Excess Heat Capacity at Low Temperatures}

Glasses reveal the universal features of their thermal properties at low temperatures. The heat capacity shows an excess part and the thermal conductivity has a plateau at around $10 \mathrm{~K}[22,23]$. These anomalous behaviors are closely related to the phonon dispersion in the terahertz frequency $(\mathrm{THz})$ range. The excess heat capacity has been observed as the deviation from the Debye $T^{3}$ law at low temperatures. The broad peak in a $\mathrm{C}_{\mathrm{p}} / T^{3}$ vs. $T$ plot is observed by this non-Debye excess heat capacity, where $C_{p}$ is the heat capacity at a constant pressure. In the $B_{2} \mathrm{O}_{3}$ glass, the peak of $C_{p} / T^{3}$ was observed at the peak temperature, $T_{\mathrm{m}}=5.8 \mathrm{~K}$ [24]. The origin of a peak is the low-energy excess part of the vibrational density of states (VDoS) over the Debye model defined by $g(E) / E^{2}$, where $g(E)$ is VDoS. The peak of $\mathrm{g}(\mathrm{E}) / \mathrm{E}^{2}$ has also been observed in the $\mathrm{THz}$ range of the inelastic scattering spectra, which is called the boson peak (BP) $[23,25]$. The temperature dependences of the heat capacity of the single-alkali borate glasses, $0.22 \mathrm{M}_{2} \mathrm{O}-0.78 \mathrm{~B}_{2} \mathrm{O}_{3}(\mathrm{M}=\mathrm{Li}, \mathrm{Na}, \mathrm{K}, \mathrm{Rb}, \mathrm{Cs})$, were reported between $2 \mathrm{~K}$ and $150 \mathrm{~K}$ by the relaxation method [26]. With an increase in the ionic radius of the alkali ion, the $T_{\mathrm{m}}$ of $\mathrm{C}_{\mathrm{p}} / \mathrm{T}^{3}$ decreases. This fact is attributed to the enhancement of the contraction of the boron-oxygen network by the increase in the alkali charge density due to the decrease in the alkali ionic radius. It was found that the $T_{\mathrm{m}}$ is proportional to the shear modulus $\mu$ measured by an ultrasonic method.

The temperature dependences of the heat capacity $\mathrm{C}_{\mathrm{p}}$ of the mixed-alkali borate glasses, $0.11 \mathrm{M}_{2} \mathrm{O}-0.11 \mathrm{M}_{2}^{\prime} \mathrm{O}-0.78 \mathrm{~B}_{2} \mathrm{O}_{3}\left(\mathrm{M}, \mathrm{M}^{\prime}=\mathrm{Li}, \mathrm{K}\right.$, and $\left.\mathrm{Cs}\right)$, were measured using a relaxation calorimeter to investigate the MAE [27]. In order to discuss the excess heat capacity, the temperature dependence of $\mathrm{C}_{\mathrm{p}} / \mathrm{T}^{3}$ of a mixed-lithium cesium ( $\mathrm{LiCs}$ ) borate glass $\left(\mathrm{M}=\mathrm{Li}, \mathrm{M}^{\prime}=\mathrm{Cs}\right)$ is plotted to investigate the deviation from the Debye $T^{3}$ law at low temperatures as shown in Figure 5a, where the dependences of the single-cesium borate $\left(M=M^{\prime}=C s\right)$ and single-lithium borate $\left(M=M^{\prime}=L i\right)$ glasses are also plotted for comparison [26]. The broad peaks of $C_{\mathrm{p}} / T^{3}$ were observed with the $T_{\mathrm{m}}$ in the range $5-15 \mathrm{~K}$ for all three glasses. To clarify the MAE, the $T_{\mathrm{m}}$ of the single-alkali and mixed-alkali borate glasses was plotted versus the ionic radius of alkali ion as shown in Figure $5 b$, where the ionic radius of the mixed-alkali glass is the arithmetical mean of the radius of the two alkali ions. The significant negative deviation of $T_{\mathrm{m}}$ of a mixed-cesium lithium borate glass from that of linearity of the single-alkali borate 
glasses between the alkali cation size and $T_{\mathrm{m}}$ was clearly observed. When two dissimilar alkali species are co-doped, a different modification of the boron-oxygen network appears. The number of the $\mathrm{B}_{4}{ }^{-}$units, $\mathrm{N}_{4}$, in a mixed-alkali glass was lower than the value expected from that of a single-alkali borate glass. The result of molecular dynamic simulations predicted that the $\mathrm{N}_{4}$ decreases from lithium to cesium in the mixed-cesium lithium glasses [20]. The negative deviation of $T_{\mathrm{m}}$ in the mixed-cesium lithium glass can be attributed to the decrease in the $\mathrm{N}_{4}$ caused by the dissimilar alkali mixing. The existence of the $(\mathrm{CsLi})^{2+}$ dissimilar pair may be the origin of the negative deviation in Figure 5b.

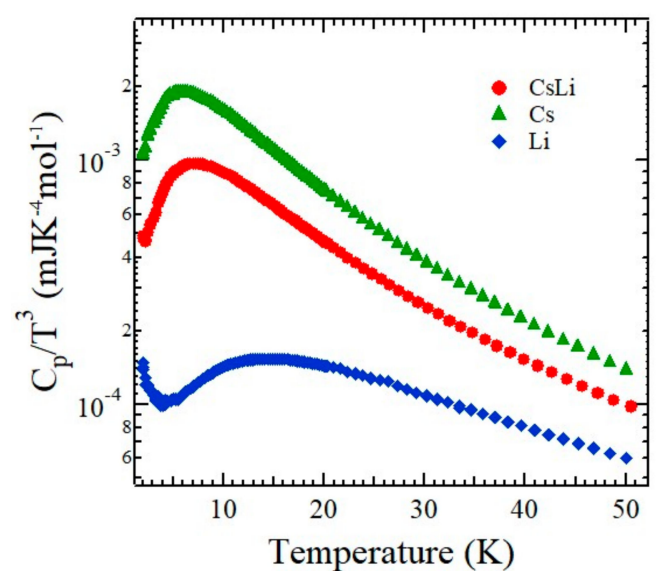

(a)

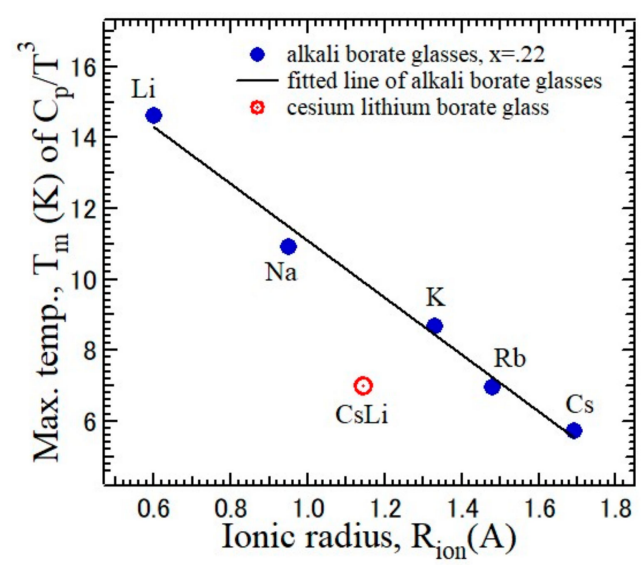

(b)

Figure 5. (a) Excess heat capacity of the single-alkali borate glasses, $0.22 \mathrm{M}_{2} \mathrm{O}-0.78 \mathrm{~B}_{2} \mathrm{O}_{3}(\mathrm{M}=\mathrm{Li}, \mathrm{Cs})$, and mixed-alkali borate glasses, $0.11 \mathrm{Cs}_{2} \mathrm{O}-0.11 \mathrm{Li}_{2} \mathrm{O}-0.78 \mathrm{~B}_{2} \mathrm{O}_{3}(\mathrm{CsLi}) ;(\mathbf{b})$ mixed alkali effect on the maximum temperatures of $\mathrm{C}_{\mathrm{p}} / \mathrm{T}^{3}$ vs. ionic radius of alkali ion of the single-alkali borate glasses, $0.22 \mathrm{M}_{2} \mathrm{O}-0.78 \mathrm{~B}_{2} \mathrm{O}_{3}(\mathrm{M}=\mathrm{Li}, \mathrm{Na}, \mathrm{K}, \mathrm{Rb}$, and $\mathrm{Cs})$ and the mixed-alkali borate glasses, $0.11 \mathrm{Cs}_{2} \mathrm{O}-0.11 \mathrm{Li}_{2} \mathrm{O}-0.78 \mathrm{~B}_{2} \mathrm{O}_{3}$ (CsLi) [27].

\section{Elastic Properties}

\subsection{Longitudinal Modulus}

The elastic properties are also sensitive for the network structure of the glasses. Since glasses are isotropic, the following elastic constants are defined, where $V_{\mathrm{L}}$ and $V_{\mathrm{T}}$ are the longitudinal and transverse sound velocities, respectively, and $\rho$ is the density:

$$
\begin{gathered}
\text { Poisson's ratio: } \sigma=\left(\mathrm{V}_{\mathrm{L}}^{2}-2 \mathrm{~V}_{\mathrm{T}}^{2}\right) / 2\left(\mathrm{~V}_{\mathrm{L}}{ }^{2}-\mathrm{V}_{\mathrm{T}}{ }^{2}\right) \\
\text { Longitudinal modulus: } \mathrm{L}=\rho \mathrm{VL} 2 \\
\text { Shear modulus: } \mu=\rho \mathrm{V}_{\mathrm{T}}{ }^{2}
\end{gathered}
$$

In the single-alkali borate glasses, the longitudinal and transverse sound velocities were determined by ultrasonic pulse-echo methods at $10 \mathrm{MHz}$. The various elastic constants reveal the remarkable and non-linear dependences on the alkali contents. For example, the alkali content dependences of the longitudinal modulus, $\mathrm{L}$, of alkali borate glasses are shown in Figure 6a [4].

For the single-alkali borate glasses, $x \mathrm{M}_{2} \mathrm{O}-(1-x) \mathrm{B}_{2} \mathrm{O}_{3}(\mathrm{M}=\mathrm{Li}, \mathrm{Na}, \mathrm{K}, \mathrm{Rb}$, and $\mathrm{Cs})$ in the low alkali content range of $0 \leq x \leq 0.1$, the plot of $L$ versus the alkali content monotonically increases in the same way irrespective of the difference in the alkali ions [4]. This means that all kinds of alkali ions fill the voids of the initial $\mathrm{B}_{2} \mathrm{O}_{3}$ glass network in the same way. Above the content of $x=0.1$, the elastic constants depend both on the species of the alkali ion, $\mathrm{M}^{+}$, and their content, $x$. These variations of $\mathrm{L}$ in the range $x>0.1$ are related to the short-range three structural units, namely $\mathrm{B}_{3}, \mathrm{M}^{+} \mathrm{B}_{4}{ }^{-}$, and $\mathrm{M}^{+} \mathrm{BO}_{2}{ }^{-}$. The $\mathrm{L}$ value increases when the structural unit $\mathrm{M}^{+} \mathrm{B}_{4}{ }^{-}$is formed, while $\mathrm{L}$ decreases 
when the other structural unit $\mathrm{M}^{+} \mathrm{BO}_{2}{ }^{-}$is formed. There is a correlation between the $\mathrm{L}$ value and the mole fraction of $\mathrm{M}^{+} \mathrm{B}_{4}{ }^{-}$or $\mathrm{M}^{+} \mathrm{BO}_{2}{ }^{-}$, denoted by $\mathrm{m}_{4}$ or by $\mathrm{m}_{2}$, respectively.

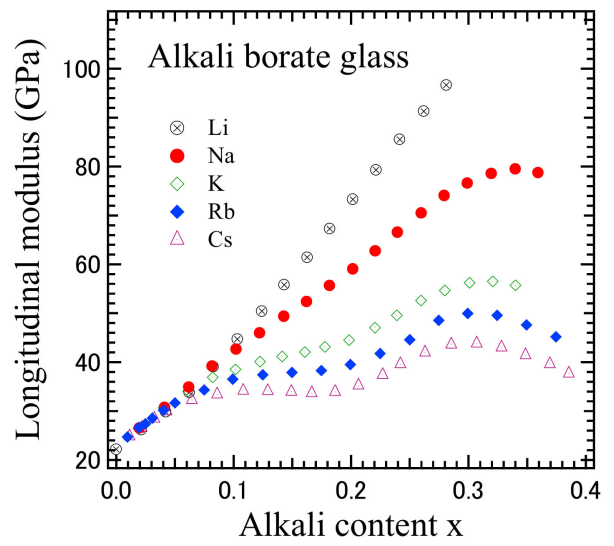

(a)

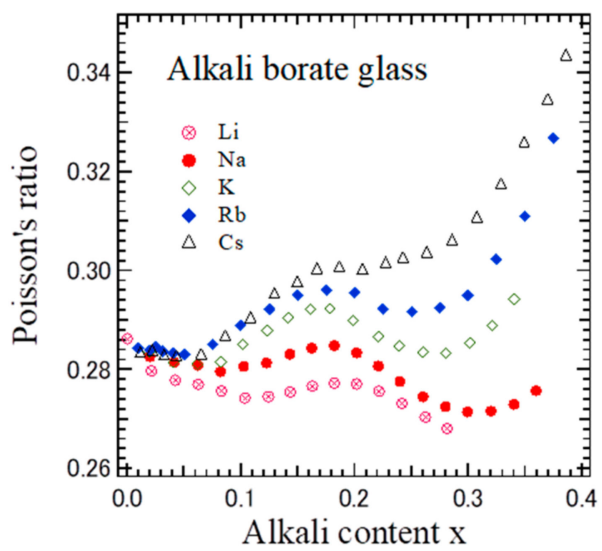

(b)

Figure 6. Alkali content dependences of (a) longitudinal modulus, L.; (b) Poisson's ratio, $\sigma$, of the single-alkali borate glasses, $x \mathrm{M}_{2} \mathrm{O}-(1-x) \mathrm{B}_{2} \mathrm{O}_{3}(\mathrm{M}=\mathrm{Li}, \mathrm{Na}, \mathrm{K}, \mathrm{Rb}$, and Cs) [4].

In the single-lithium borate glass, $\mathrm{L}$ monotonically increases with the increase in $x$ over the bulk glass formation range below $x=0.28$, which is about 0.1 smaller than the other single-alkali borate glasses. This means that the formation of $\mathrm{Li}^{+} \mathrm{BØ}_{4}{ }^{-}$dominates over the formation of $\mathrm{Li}^{+} \mathrm{BO}_{2}{ }^{-}$. Therefore, it holds that $\mathrm{m}_{4}>>\mathrm{m}_{2}$ for the lithium borate glasses. In contrast, the $\mathrm{L}$ of the cesium borate glasses exhibits two peaks at about $x=0.10$ and 0.30 , and such variation in $\mathrm{L}$ is approximately divided into four characteristic $x$ ranges:

(I) the first range between $x=0$ and 0.10 is defined as the range between the pure $\mathrm{B}_{2} \mathrm{O}_{3}$ and the first maximum at about $x=0.10$. With the addition of $\mathrm{M}_{2} \mathrm{O}(\mathrm{M}=\mathrm{Li}, \mathrm{Na}, \mathrm{K}, \mathrm{Rb}$, and $\mathrm{Cs})$ to $\mathrm{B}_{2} \mathrm{O}_{3}, \mathrm{~B}_{3}$ is converted only into $\mathrm{M}^{+} \mathrm{B}_{4}{ }^{-}$and no $\mathrm{M}^{+} \mathrm{BO}_{2}{ }^{-}$is formed in this range.

(II) the second range between $x=0.10$ and 0.20 is defined as the range between the first maximum at about $x=0.10$ and the minimum at about $x=0.20$. L decreases as the alkali ions are changed from $\mathrm{Li}^{+}$to $\mathrm{Cs}^{+}$. As a result, the mole fraction of $\mathrm{M}^{+} \mathrm{BO}_{2}{ }^{-}$increases, while the mole fraction of $\mathrm{M}^{+} \mathrm{B}_{4}{ }^{-}$decreases from the sodium to cesium borate glasses.

(III) the third range between $x=0.20$ and 0.30 is defined as the range between the minimum at about $x=0.20$ and the second maximum at about $x=0.30$. L decreases from the lithium to cesium borate glasses, while $\mathrm{L}$ in the third range is greater than that in the second range. The mole fraction of $\mathrm{M}^{+} \mathrm{BØ}_{4}{ }^{-}$increases, while the mole fraction of $\mathrm{M}^{+} \mathrm{BO}_{2}{ }^{-}$decreases from the sodium to cesium borate glasses. As a result, $x_{2}$ takes a maximum at about $x=0.20$.

(IV) the fourth range of $x \geq 0.30$ is defined as the range above the second maximum at about $x=0.30$. L gradually increases, then decreases in this range except for the lithium borate glass. As a result, no more $\mathrm{M}^{+} \mathrm{B}_{4}{ }^{-}$is formed in this range. The second maximum at about $x=0.30$ is caused by the conversion of the residual $\mathrm{B}_{3}$ into only $\mathrm{M}^{+} \mathrm{BO}_{2}{ }^{-}$.

\subsection{Poisson's Ratio}

Poisson's ratio, $\sigma$, is defined as the ratio between the transverse contraction strain and longitudinal extension strain in a stretched bar. Previous studies of the relation of the Poisson's ratio with the glass structure showed that it was greater than 0.25 when the ions themselves are deformed under stress in addition to the network distortion $[28,29]$. The alkali content dependences of Poisson's ratio, $\sigma$, of the single-alkali borate glasses are shown in Figure 6b. All the values of the Poisson's ratio are greater than 0.25 in the single-alkali borate glasses, and alkali ions themselves are deformed under stress. In all the single-alkali borate glasses, two minima appear, except for the lithium borate glass, due to the lower 
maximum of the Li content of 0.27 . Since the Poisson's ratio is related to the glass network connectivity, it is governed by the middle range super-structural borate groups. The behavior of the Poisson's ratio is complicated, while it may be caused by the following two factors for this behavior:

(I) One factor is the disproportionation reaction, $\mathrm{M}^{+} \mathrm{BØ}_{4}{ }^{-} \Rightarrow \mathrm{M}^{+} \mathrm{BO}_{2}{ }^{-}$, between the borate structural units. The presence of $\mathrm{M}^{+} \mathrm{B}_{4}{ }^{-}$, whose network connectivity is four, increases the connectivity with the surrounding (super) structural units, while the presence of $\mathrm{M}^{+} \mathrm{BO}_{2}{ }^{-}$, whose network connectivity is two, decreases the connectivity with the surrounding (super) structural units.

(II) The other factor is the presence of super-structural units, especially the pentaborate group, $\mathrm{B}_{5} \mathrm{O}_{6} \varnothing_{4}{ }^{-}$. The $\mathrm{B}_{4}{ }^{-}$unit that is included in a pentaborate group, whose network connectivity is also four, does not contribute to the connectivity with the surrounding (super) structural units, while the $\mathrm{B}_{4}{ }^{-}$unit itself in the pentaborate group contributes to L. Thus, the rigidity and the network connectivity are not the same concept. The presence of pentaborate groups was reported by a Raman spectroscopic study of the single-alkali borate glasses [30].

The elastic properties of the mixed-cesium lithium borate glasses, $0.28\left\{(1-y) \mathrm{Cs}_{2} \mathrm{O}-y \mathrm{Li}_{2} \mathrm{O}\right\}-0.72 \mathrm{~B}_{2} \mathrm{O}_{3}$, were studied by Brillouin scattering. The right-angle scattering spectrum of a glass at $y=0.9$ is shown in Figure 7a [22]. Peaks of the longitudinal acoustic (LA) and transverse acoustic (TA) modes were clearly observed. The Li fraction dependence of the LA and TA velocities for a constant alkali content were determined from the frequency shifts as shown in Figure $7 \mathrm{~b}$.

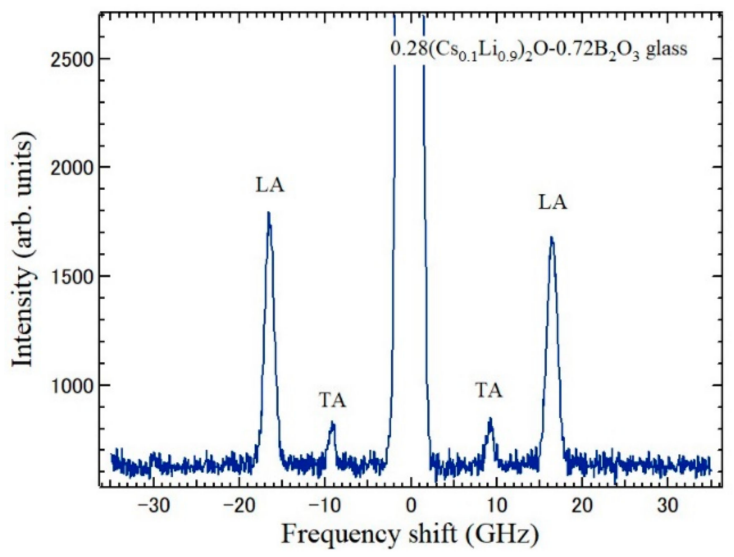

(a)

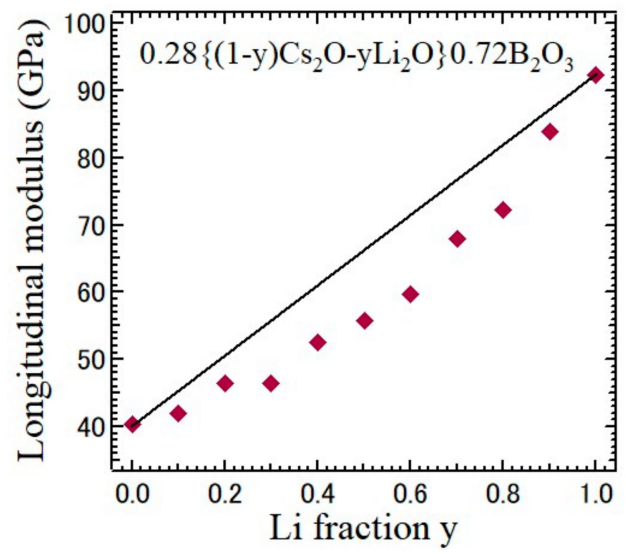

(c)

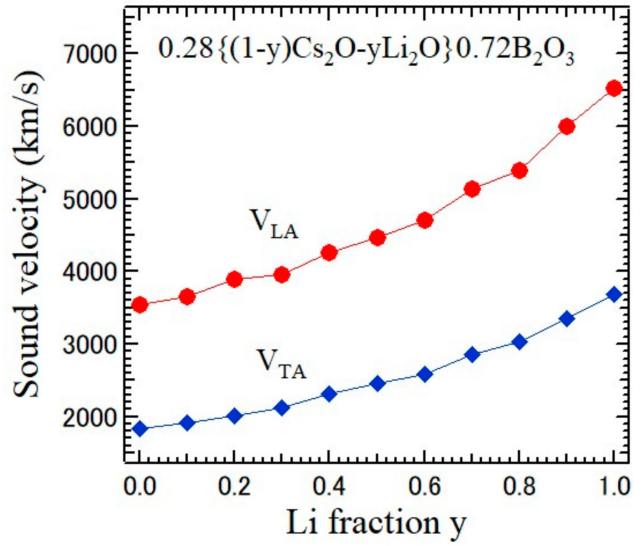

(b)

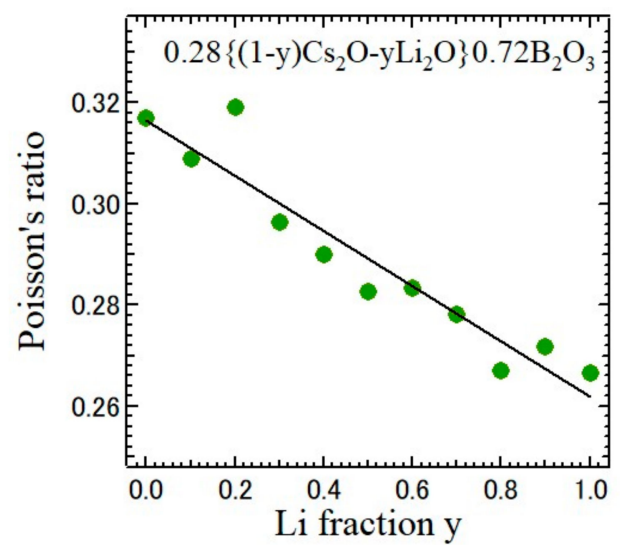

(d)

Figure 7. (a) Brillouin scattering spectrum of the mixed-cesium lithium borate glasses, $0.28\left\{0.1 \mathrm{Cs}_{2} \mathrm{O}\right.$ $0.9 \mathrm{Li}_{2} \mathrm{O}-0.72 \mathrm{~B}_{2} \mathrm{O}_{3}$. Li fraction $y$ dependences of (b) LA and TA velocity; (c) longitudinal modulus $\mathrm{L}$; (d) Poisson's ratio $\sigma$ of the mixed-cesium lithium borate glasses, $0.28\left\{(1-y) \mathrm{Cs}_{2} \mathrm{O}-y \mathrm{Li}_{2} \mathrm{O}\right\}-0.72 \mathrm{~B}_{2} \mathrm{O}_{3}$. The solid lines show the linear relations in (c,d) [22]. 
With the increase in the Li fraction $y$, the longitudinal modulus, $\mathrm{L}$, determined from the LA velocity increases as shown in Figure 7c. From the lithium to cesium borate glasses, the mole fraction of $\mathrm{M}^{+} \mathrm{B}_{4}{ }^{-}$decreases, while the mole fraction of $\mathrm{M}^{+} \mathrm{BO}_{2}{ }^{-}$increases. The negative deviation was observed from a linear dependence of the $\mathrm{L}$ in Figure $7 \mathrm{c}$. A similar negative deviation was also observed in the mixed-cesium lithium borate glasses, $0.25\left\{(1-y) \mathrm{Cs}_{2} \mathrm{O}-y \mathrm{Li}_{2} \mathrm{O}\right\}-0.75 \mathrm{~B}_{2} \mathrm{O}_{3}$ [31]. These deviations show the enhancement of the change from the $\mathrm{M}^{+} \mathrm{B}_{4}{ }^{-}$to $\mathrm{M}^{+} \mathrm{BO}_{2}{ }^{-}$units caused by the appearance of dissimilar $(\mathrm{CsLi})^{2+}$ pairs.

In the mixed-cesium lithium borate glasses, Poisson's ratio was determined from the LA and TA velocities as shown in Figure $7 \mathrm{~d}$. The values of the Poisson's ratio are greater than 0.25 , and alkali ions themselves are deformed under stress in the mixed-alkali borate glasses. The Poisson's ratio shows a monotonic decrease with the increasing lithium fraction. The scattering of the data points was caused by the weak intensity of the TA peaks in the Brillouin scattering spectra as shown in Figure 7a. No noticeable MAE was observed for Poisson's ratio within the experimental uncertainty. It suggests that the influence of the MAE is slight for the glass network connectivity.

\subsection{Cauchy-Type Relation}

In isotropic systems, the number of independent elastic constants is only two, namely, the longitudinal ( $\mathrm{L}$ or $\mathrm{c}_{11}$ ) and shear ( $\mu$ or $\mathrm{c}_{44}$ ) moduli, where $\mathrm{c}_{11}$ and $\mathrm{c}_{44}$ are the elastic stiffness constants. Additional local symmetry conditions further reduce the number of independent elastic constants. The $\mathrm{L} / \mu$ ratio is an indicator of the character of the force field; if atoms interact through a central potential, $\mathrm{L} / \mu=3$, but if through a noncentral potential, $\mathrm{L} / \mu>3$ [32]. However, most glasses are far from the central potential and the Cauchy relation, $\mathrm{L}=3 \mu$. The Cauchy-type relation, $\mathrm{L}=\mathrm{A}+\mathrm{B} \mu$ with $B \sim 3$, was reported to hold for the high frequency limit values of the $L$ and the $\mu$ for some types of glasses, where $\mathrm{A}$ is the material dependent constant [29,33].

The Cauchy-type relation holds well for the single-alkali borate and mixed-cesium lithium borate glasses as shown in Figure 8a,b, respectively [4,22]. The fitted values of the single-alkali borate glasses are $\mathrm{A}=2.3 \mathrm{GPa}$ and $\mathrm{B}=3.1$; the two values do not show a difference between the alkali ions. However, the fitted values of the mixed-cesium lithium borate glasses are $\mathrm{A}=9.9 \mathrm{GPa}$ and $\mathrm{B}=2.8$. For both glasses, the value of $B$ is about 3 , while the value of the mixed-cesium lithium borate glasses is slightly lower. The large value of A of the mixed-cesium lithium borate glasses may suggest that the MAE may induce a local anisotropy and enhance the deviation.

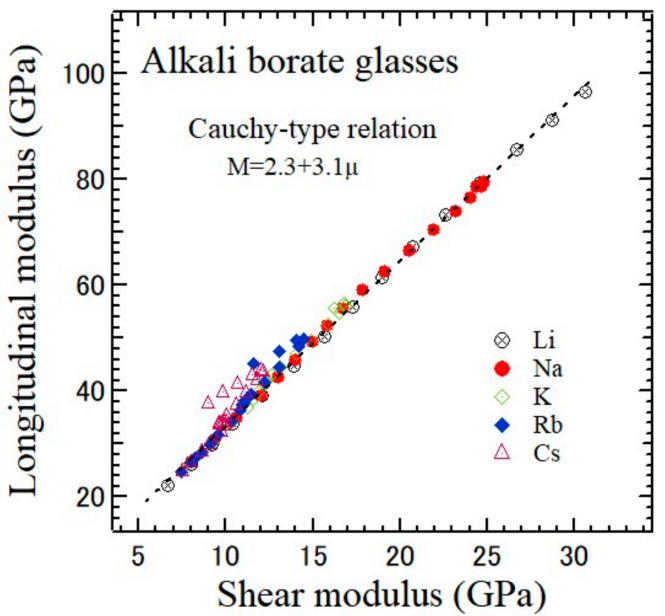

(a)

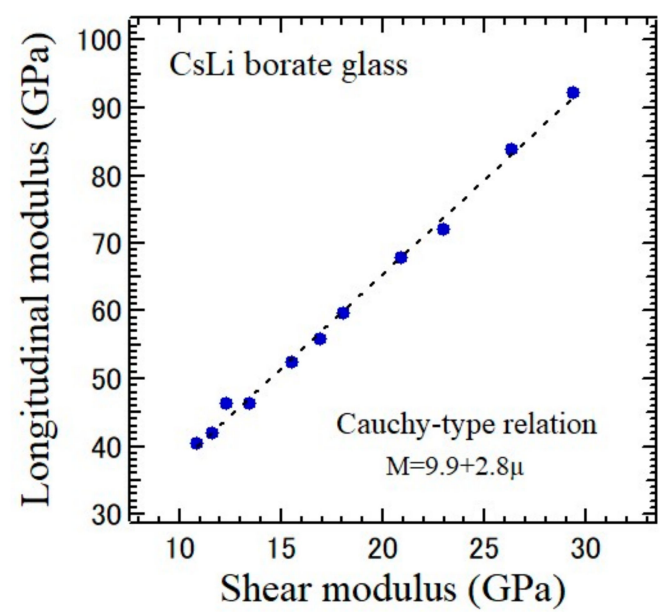

(b)

Figure 8. Cauchy-type relation of (a) the single-alkali borate glasses, $x \mathrm{M}_{2} \mathrm{O}(1-x) \mathrm{B}_{2} \mathrm{O}_{3}(\mathrm{M}=\mathrm{Li}, \mathrm{Na}, \mathrm{K}$, $\mathrm{Rb}$, and Cs) [4]; (b) the mixed-cesium lithium borate glasses, $0.28\left\{(1-y) \mathrm{Cs}_{2} \mathrm{O}-y \mathrm{Li}_{2} \mathrm{O}\right\}-0.72 \mathrm{~B}_{2} \mathrm{O}_{3}$ [22]. 


\section{Vibrational Properties}

Vibrational spectroscopy, such as Raman scattering and infrared (IR) spectroscopy, is a powerful tool to study the local atomic structure of condensed matters, especially glasses with random structures. When a center of symmetry exists, the exclusion principle holds, namely, the Raman active mode is IR inactive and the IR active mode is Raman inactive. However, glass has no center of symmetry due to its random structure. Generally, the modes higher than $200 \mathrm{~cm}^{-1}$ are the internal mode of a molecule and the modes lower than $200 \mathrm{~cm}^{-1}$ are the external modes reflecting the intermolecular interaction. In glasses the modes higher than $200 \mathrm{~cm}^{-1}$ originate from groups of molecules and the structural units. While the modes lower than $200 \mathrm{~cm}^{-1}$ originate from the vibrational modes of medium range order of the glass network structure, and the lowest frequency broad peak below $200 \mathrm{~cm}^{-1}$ is called a boson peak. As discussed in Section 3, a boson peak is the low-energy excess part of the vibrational density of states (VDoS). Typical Raman scattering spectra of the alkali borate glasses between 10 1700 $\mathrm{cm}^{-1}$ are shown in Figure 9 [22,34-36]. The remarkable variation of boson peaks below $200 \mathrm{~cm}^{-1}$ was clearly observed. In addition the high frequency Raman bands above $200 \mathrm{~cm}^{-1}$ also shows a noticeable variation, especially the middle frequency range between 700 and $850 \mathrm{~cm}^{-1}$, where the modes of various structural units, such as the boroxol ring, pentaborate borate, metaborate groups, etc., were observed [37].

\subsection{Internal Raman Bands}

The intense and sharp peak at $808 \mathrm{~cm}^{-1}$ of the $\mathrm{B}_{2} \mathrm{O}_{3}$ glass in Figure 9 is the localized symmetric breathing mode of the $\mathrm{B}_{3} \mathrm{O}_{3}$ planer boroxol ring with the coordination number of boron is three. When the $\mathrm{B}_{2} \mathrm{O}_{3}$ glass is modified by alkali ions, the coordination number of boron changes to four. As shown in Figure 9, for the $0.28 \mathrm{Cs}_{2} \mathrm{O}-0.72 \mathrm{~B}_{2} \mathrm{O}_{3}$ and $0.28 \mathrm{Li}_{2} \mathrm{O}-0.72 \mathrm{~B}_{2} \mathrm{O}_{3}$ glasses, the intense peak appears at $758 \mathrm{~cm}^{-1}$ and $777 \mathrm{~cm}^{-1}$, respectively [34]. The $0.14 \mathrm{Cs}_{2} \mathrm{O}-0.14 \mathrm{Li}_{2} \mathrm{O}-0.72 \mathrm{~B}_{2} \mathrm{O}_{3}$ glass shows the intense peak at $770 \mathrm{~cm}^{-1}$. The Raman scattering spectra of the $0.28\left\{(1-y) \mathrm{Cs}_{2} \mathrm{O}-y \mathrm{Li}_{2} \mathrm{O}\right\}-0.72 \mathrm{~B}_{2} \mathrm{O}_{3}$ glasses with $y=0.2,0.5$, and 0.8 between 650 and $850 \mathrm{~cm}^{-1}$ are shown in Figure 10a [22]. According to the analysis of the internal Raman bands, the average characteristic mode frequency of the pentaborate, dipentaborate, and chain type metaborate groups are 770,755 and $730 \mathrm{~cm}^{-1}$, respectively.

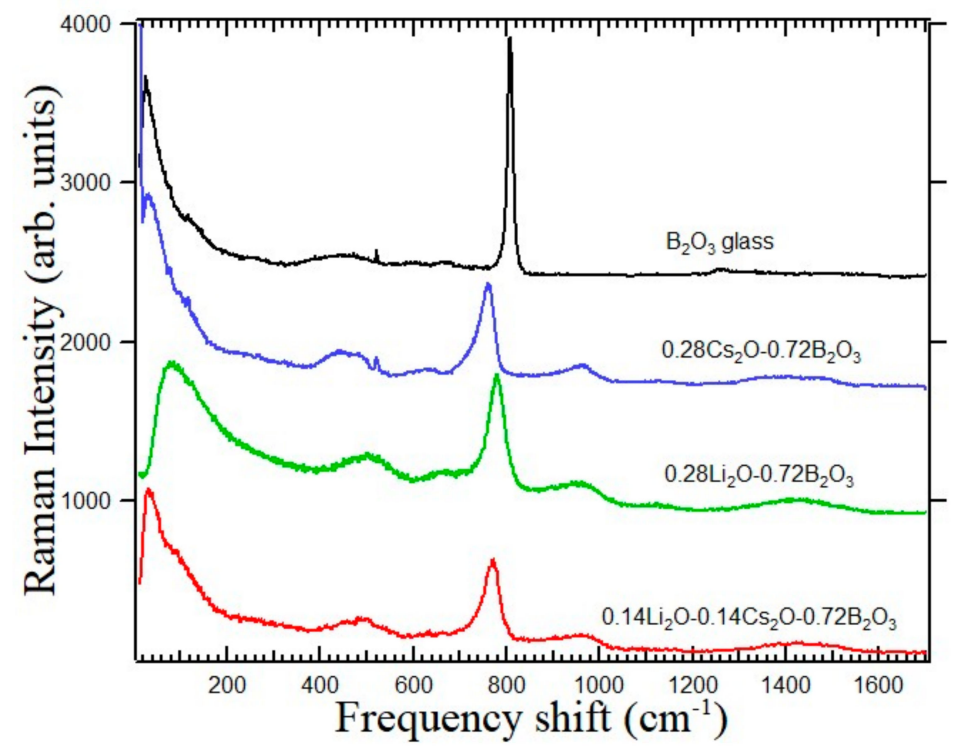

Figure 9. Broadband Raman scattering spectra of the $\mathrm{B}_{2} \mathrm{O}_{3}, 0.28 \mathrm{Li}_{2} \mathrm{O}-0.72 \mathrm{~B}_{2} \mathrm{O}_{3}, 0.28 \mathrm{Cs} \mathrm{s}_{2} \mathrm{O}-0.72 \mathrm{~B}_{2} \mathrm{O}_{3}$, and $0.14 \mathrm{Cs}_{2} \mathrm{O}-0.14 \mathrm{Li}_{2} \mathrm{O}-0.72 \mathrm{~B}_{2} \mathrm{O}_{3}$ glasses $[22,34,35]$.

These band intensities were determined by a multi-peaks fitting. The intensities of these three characteristic modes as a function on the Li fraction are shown in Figure 10b. As the Li fraction $y$ 
increases with a constant alkali content, the pentaborate groups increase, while the dipentaborate and chain type metaborate groups decrease. These dependences of the mode intensities are not linear with the Li fraction $y$, and such nonlinear changes of the structural units can be caused by the MAE.

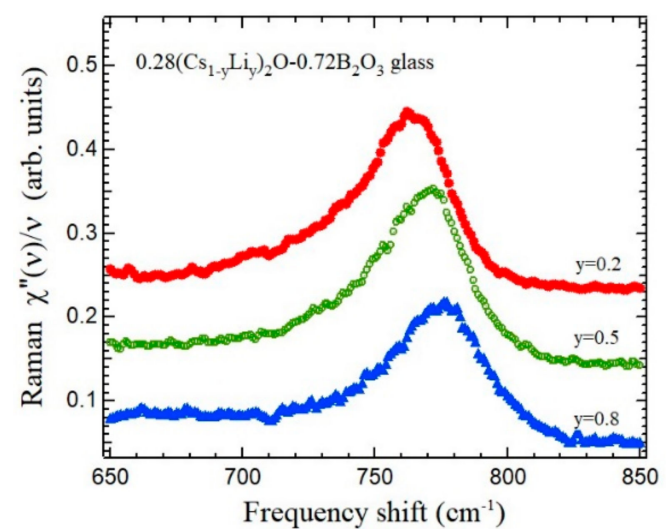

(a)

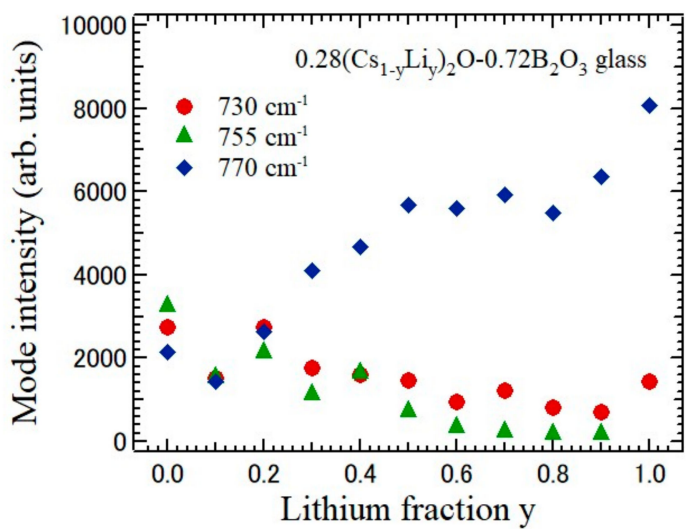

(b)

Figure 10. (a) Raman scattering spectra of internal vibrational modes of the mixed-cesium lithium borate glasses, $0.28\left\{(1-y) \mathrm{Cs}_{2} \mathrm{O}-y \mathrm{Li}_{2} \mathrm{O}\right\}-0.72 \mathrm{~B}_{2} \mathrm{O}_{3}$ at $y=0.2,0.5$, and 0.8.; (b) the Li fraction dependence of mode intensities at 730, 755, and $770 \mathrm{~cm}^{-1}$ [22].

\subsection{Boson Peaks}

In Figure 9, the boson peak spectrum of the $\mathrm{B}_{2} \mathrm{O}_{3}$ glass is well fitted by a log-normal function and its peak frequency is $26 \mathrm{~cm}^{-1}$. According to the vibrational study by hyper-Raman scattering, the origin of the boson peak is attributed to the librational motions of two adjacent boroxole rings [38]. As shown Figure 9, the boson peak frequency of the $0.28 \mathrm{Cs}_{2} \mathrm{O}-0.72 \mathrm{~B}_{2} \mathrm{O}_{3}$ glass at $26 \mathrm{~cm}^{-1}$ is nearly same as that of the $\mathrm{B}_{2} \mathrm{O}_{3}$ glass, while that of the $0.28 \mathrm{Li}_{2} \mathrm{O}-0.72 \mathrm{~B}_{2} \mathrm{O}_{3}$ glass at $72 \mathrm{~cm}^{-1}$ is about three times of that of the $\mathrm{B}_{2} \mathrm{O}_{3}$ glass. The $\mathrm{Cs}$ ions with a large ionic size only slightly changes the boron-oxgen network structure by the low charge density. However, the Li ions with a small ionic size cause shrinking of the boron-oxygen network structure by the high charge density [26,39]. By application of high pressure, it was reported that the boson peak frequency significantly increases up to $68 \mathrm{~cm}^{-1}$ at $4 \mathrm{GPa}$ by shrinking of the boron-oxygen network structure [40].

Figure 11 shows the relation between the boson peak frequency determined by Raman scattering versus the shear modulus determined by the ultrasonic method in the single-alkali borate glasses. The solid circles denote the values of the $0.28 \mathrm{M}_{2} \mathrm{O}-0.72 \mathrm{~B}_{2} \mathrm{O}(\mathrm{M}=\mathrm{Li}, \mathrm{Na}, \mathrm{K}, \mathrm{Rb}$, and $\mathrm{Cs})$ and the open circle denotes the value of the $0.14 \mathrm{Cs}_{2} \mathrm{O}-0.14 \mathrm{Li}_{2} \mathrm{O}-0.72 \mathrm{~B}_{2} \mathrm{O}_{3}(\mathrm{CsLi})$ glasses $[4,21]$. The deviation of the plot of the mixed-cesium lithium borate glass (CsLi) from the linear relation of single-alkali borate glasses in Figure 11 may suggest the MAE. 


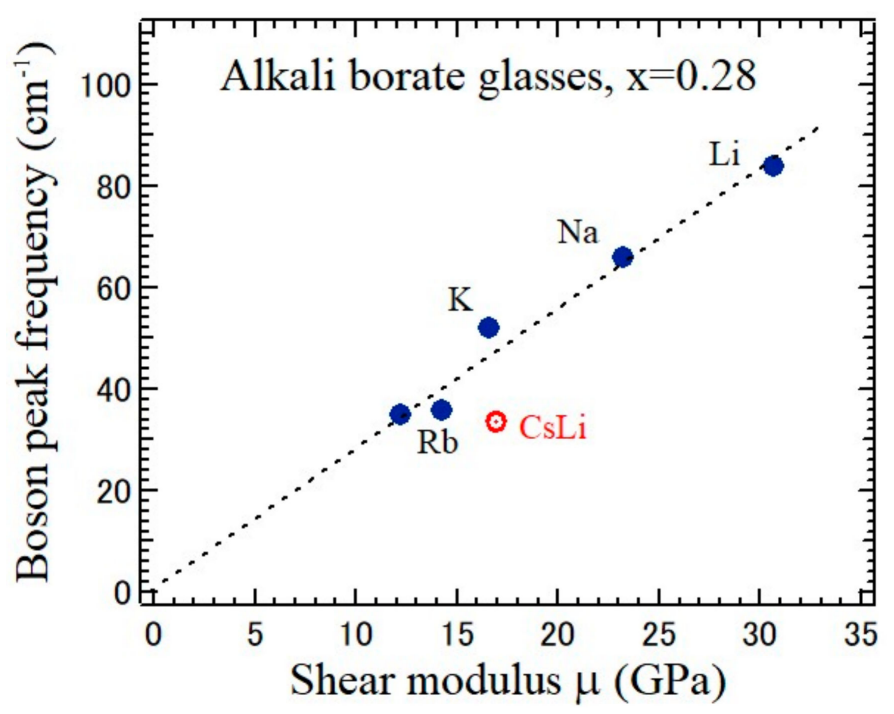

Figure 11. The relation between the boson peak frequency determined by Raman scattering versus the shear modulus determined by ultrasonic method in the alkali borate glasses. Solid circles denote the values of the single-alkali borate glasses, $0.28 \mathrm{M}_{2} \mathrm{O}-0.72 \mathrm{~B}_{2} \mathrm{O}_{3}(\mathrm{M}=\mathrm{Li}, \mathrm{Na}, \mathrm{K}, \mathrm{Rb}$, and $\mathrm{Cs})$, and the open circle denotes the value of the mixed-cesium lithium glasses, $0.14 \mathrm{Cs}_{2} \mathrm{O}-0.14 \mathrm{Li}_{2} \mathrm{O}-0.72 \mathrm{~B}_{2} \mathrm{O}_{3}(\mathrm{CsLi})$.

The boson peak spectra of the mixed-cesium lithium $0.28\left\{(1-y) \mathrm{Cs}_{2} \mathrm{O}-y \mathrm{Li}_{2} \mathrm{O}\right\}-0.72 \mathrm{~B}_{2} \mathrm{O}_{3}$ glasses were studied by Raman scattering and splitting of the boson peak was observed [21]. The results of fitting of the boson peak spectrum of the $0.28\left\{0.2 \mathrm{Cs}_{2} \mathrm{O}-0.8 \mathrm{Li}_{2} \mathrm{O}\right\}-0.72 \mathrm{~B}_{2} \mathrm{O}_{3}$ glass $(y=0.8)$ between 10 and $200 \mathrm{~cm}^{-1}$ are shown in Figure 12 [21]. The boson peak of the single-alkali borate glasses is well fitted by a log-normal function. However, the boson peak of the mixed-alkali borate glasses has a distorted broad peak and such a single mode fitting is impossible. Therefore, the broad peak is fitted by two log-normal functions.

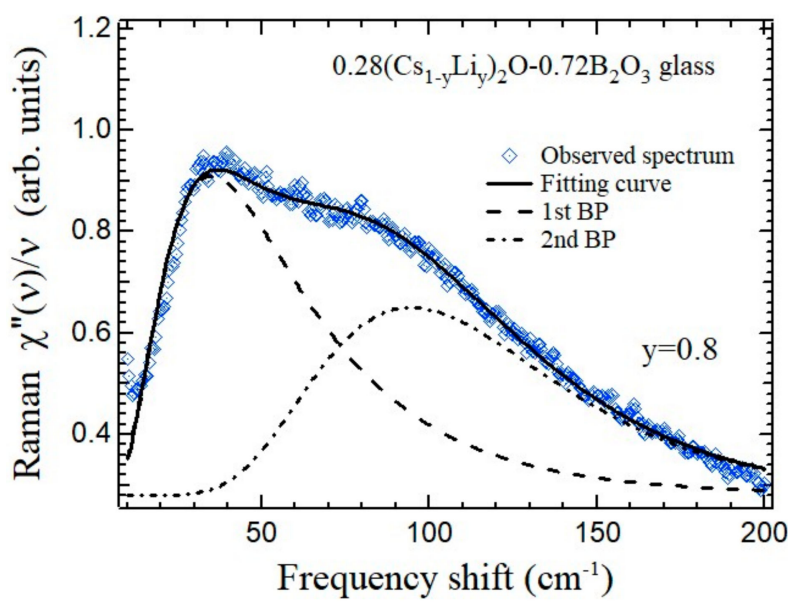

Figure 12. Raman scattering spectrum of boson peaks of the mixed-cesium lithium borate glasses, $0.28\left\{0.2 \mathrm{Cs}_{2} \mathrm{O}-0.8 \mathrm{Li}_{2} \mathrm{O}\right\}-0.72 \mathrm{~B}_{2} \mathrm{O}_{3}$ [21].

The fitted results indicate the splitting of a boson peak in the mixed-cesium lithium borate glasses. The origin of this splitting is probably related to two kinds of structural correlations related to the heterogeneous structure including the Cs-rich and Li-rich regions. The static structure factor, $\mathrm{S}_{\mathrm{CsLi}}(\mathrm{Q})$, of the mixed-cesium lithium borate glasses cannot be reproduced by the average between $S_{C S}(Q)$ of the cesium borate and $\mathrm{S}_{\mathrm{Li}}(\mathrm{Q})$ of the lithium borate glasses [41]. This fact means that there is no phase separation into the cesium borate and lithium borate glasses. The detailed analysis of the static 
structure factor, $\mathrm{S}_{\mathrm{CsLi}}(\mathrm{Q})$, of the mixed-cesium lithium borate glasses and the boson peak spectra, $\mathrm{S}_{\mathrm{CsLi}}(\mathrm{E})$, measured by neutron scattering will be published elsewhere.

\section{Summary}

The modification of oxide glasses by dissimilar alkali ions causes a maximum in the electric resistivity or the expansion coefficient, and that is called the mixed-alkali effect (MAE). MAE is very important not only in basic sciences but also in technology, while its mechanism is not yet clarified. In order to give new insights into MAE, this paper reviews the experimental studies on the glass transition temperature, heat capacity, elastic moduli, and optical vibrations in the mixed-cesium lithium borate glasses, $x\left\{(1-y) \mathrm{Cs}_{2} \mathrm{O}-y \mathrm{Li}_{2} \mathrm{O}\right\}-(1-x) \mathrm{B}_{2} \mathrm{O}_{3}$. For the single-alkali borate glasses, $x \mathrm{M}_{2} \mathrm{O}(1-x)-\mathrm{B}_{2} \mathrm{O}_{3}$ $(\mathrm{M}=\mathrm{Li}, \mathrm{Na}, \mathrm{K}, \mathrm{Rb}$, and $\mathrm{Cs})$, the glass transition temperature, $T_{\mathrm{g}}=270{ }^{\circ} \mathrm{C}$, of the pure borate glass monotonically increases as the alkali content $x$ increases. However, for the mixed-cesium lithium borate glasses with a constant alkali content $x$, the $T_{\mathrm{g}}$ versus the lithium fraction $y$ has a minimum. The excess heat capacity at low temperatures caused by the excess vibrational density of states, and it shows the nonlinear variation against the lithium fraction $y$. The lithium fraction dependences of elastic properties are analyzed about the longitudinal modulus, Poisson's ratio, and Cauchy-type relation. In Raman scattering spectroscopy, the internal vibrational bands related to the boron-oxide structural groups shows a nonlinear variation versus the lithium fraction $y$. The boson peak of single-alkali borate glasses is a single peak, however, in the mixed-cesium lithium borate glasses the splitting of a boson peak occurs by MAE. These nonlinear behaviors on the thermal, elastic, and vibrational properties are discussed on the basis of the changes of glass network structure modified by dissimilar alkali ions. The possible origin of the MAE in the mixed borate glasses is the appearance of dissimilar alkali ion pairs with different ionic radii.

Funding: This research was funded in part by JSPS KAKENHI, Grant Number JP17K05030. The APC was funded by MDPI.

Acknowledgments: The authors thank M. Kodama, S. A. Feller, M. Affatigato, V. N. Novikov, O. Yamamuro, M. Kofu, M. Maczka, J.-H. Ko, H. Anwar, and Y. Matsuda for their collaboration and fruitful discussions. The authors also thank M. Kawashima, Y. Fukawa, K. Kaneda, S. Aramomi, and T. Sunaoshi for the experiments. This study was supported in part by JSPS KAKENHI Grant Number JP17K05030.

Conflicts of Interest: The author declares no conflict of interest.

\section{References}

1. Fajans, K.; Barber, S.W. Properties and structures of vitreous and crystalline boron oxide. J. Am. Chem. Soc. 1952, 74, 2761-2768. [CrossRef]

2. Bray, P.J. NMR studies of the structures of glasses. J. Non Cryst. Solids 1987, 95-96, 45-60. [CrossRef]

3. Kamitsos, E.I.; Chryssikos, G.D.; Karakassides, M.A. New insights into the structure of alkali borate glasses. J. Non Cryst. Solids 1990, 123, 283-285. [CrossRef]

4. Kodama, M.; Kojima, S. Velocity of sound in and elastic properties of alkali metal borate glasses. Phys. Chem. Glasses Eur. J. Glass Sci. Technol. B 2014, 55, 1-12. [CrossRef]

5. Salmon, P.S. Real space manifestation of the first sharp diffraction peak in the structure factor of liquid and glassy materials. Proc. R. Soc. Lond. A 1994, 445, 351-365.

6. Kojima, S.; Novikov, V.N.; Kofu, M.; Yamamuro, O. Nanometric Fluctuations of Sound Velocity in Alkali Borate Glasses and Fragility of Respective Melts. Phys. Status Solidi B 2020, 257, 2000073. [CrossRef]

7. Shannon, R.D.; Prewitt, C.T. Effective ionic radii in oxides and fluorides. Acta Crystallogr. Sect. B Struct. Sci. 1969, 25, 925-946. [CrossRef]

8. Giri, S.; Gaebler, C.; Helmus, J.; Affatigato, M.; Feller, S.; Kodama, M. A general study of packing in oxide glass systems containing alkali. J. Non Cryst. Solids 2004, 347, 87-92. [CrossRef]

9. Isard, J.O. The mixed alkali effect in glass. J. Non Cryst. Solids 1969, 1, 235-261. [CrossRef]

10. Day, D.E. The mixed alkali glasses-Their properties and uses. J. Non Cryst. Solids 1976, 21, $343-372$. [CrossRef] 
11. Tomozawa, M. Structure of mixed alkali glasses. J. Non Cryst. Solids 1996, 196, 280-284. [CrossRef]

12. Greaves, G.N.; Ngai, K.L. Ionic transport properties in oxide glasses derived from atomic structure. J. Non Cryst. Solids 1994, 172, 1378-1388. [CrossRef]

13. Vegiri, A.; Varsamis, C.-P.E.; Kamitsos, E.I. Molecular dynamics investigation of mixed-alkali borate glasses: Short-range order structure and alkali-ion environments. Phys. Rev. B 2009, 80, 184202. [CrossRef]

14. Kauzmann, W. The Nature of the Glassy State and the Behavior of Liquids at Low Temperatures. Chem. Rev. 1948, 43, 219-256. [CrossRef]

15. Tanaka, K. Glass Transition of Covalent Glasses. Solid State Commun. 1985, 54, 867-869. [CrossRef]

16. Micoulaut, M.; Naumis, G.G. Glass Transition Temperature Variation, Cross-Linking and Structure in Network Glasses: A Stochastic Approach. Europhys. Lett. 1999, 47, 568-574. [CrossRef]

17. Kerner, R.; Micoulaut, M. On the glass transition temperature in covalent networks. J. Non Cryst. Solids 1997, 210, 298-305. [CrossRef]

18. Zhong, J.; Bray, P.J. Change in Boron Coordination in alkali borate glasses, and mixed alkali effects, as elucidated by NMR. J. Non Cryst. Solids 1989, 111, 67-76. [CrossRef]

19. Ingram, M.D.; Moynihan, C.T.; Lesikar, A.V. Ionic conductivity and the weak electrolyte theory of glass. J. Non Cryst. Solids 1980, 38-39, 371-376. [CrossRef]

20. Kamitsos, E.I.; Yiannopoulos, Y.D.; Varsamis, C.P.; Jain, H. Structure property correlation in glasses by infrared reflectance spectroscopy. J. Non Cryst. Solids 1997, 222, 59-68. [CrossRef]

21. Kojima, S.; Anwar, H.; Ko, J.H.; Kodama, M.; Feller, S.A.; Affatigato, M.; Nieuwendaal, R.C.; Clarida, W.J.; Leelasagar, R. Brillouin and Raman spectroscopic studies of lithium caesium borate glasses. Phys. Chem. Glasses 2003, 44, 88-90.

22. Zeller, R.C.; Pohl, R.O. Thermal Conductivity and Specific Heat of Non-crystalline Solids. Phys. Rev. B 1971, 4, 2029-2040. [CrossRef]

23. Nakayama, T. Boson peak and terahertz frequency dynamics of vitreous silica. Rep. Prog. Phys. 2002, 65, 1195-1242. [CrossRef]

24. White, G.K.; Collecott, S.J.; Cook, J.S. Thermal expansion and heat capacity of vitreous $\mathrm{B}_{2} \mathrm{O}_{3}$. Phys. Rev. B 1984, 29, 4778-4781. [CrossRef]

25. Krishnan, R.S. The scattering of light in fused quartz and its Raman spectrum. Proc. Indian Acad. Sci. A 1953, 37, 377-384. [CrossRef]

26. Kojima, S.; Kawaji, H. Low-temperature heat capacity of alkali metal borate glass. J. Therm. Anal. Calorim. 2019, 135, 2759-2764. [CrossRef]

27. Kojima, S.; Kawaji, H. Low-temperature excess heat capacity and boson peak of mixed alkali effect in borate glass. Thermochim. Acta 2018, 669, 156-159. [CrossRef]

28. Chen, C.C.; Wu, Y.J.; Hwa, L.G. Temperature dependence of elastic properties of ZBLAN glasses. Mater. Chem. Phys. 2000, 65, 306-309. [CrossRef]

29. Maczka, M.; Hanuza, J.; Baran, J.; Hushur, A.; Kojima, S. Heat capacity, Raman, and Brillouin scattering studies of $\mathrm{M}_{2} \mathrm{O}-\mathrm{MgO}-\mathrm{WO}_{3}-\mathrm{P}_{2} \mathrm{O}_{5}$ glasses $(\mathrm{M}=\mathrm{K}, \mathrm{Rb})$. J. Chem. Phys. 2006, 125, 244503. [CrossRef]

30. Meera, B.N.; Ramakrishna, J. Raman spectral studies of borate glasses. J. Non Cryst. Solids 1993, 159, 1-21. [CrossRef]

31. Aramomi, S.; Matsuda, Y.; Kojima, S. High temperature Brillouin scattering study on elastic properties of lithium cesium borate glasses, crystals and melts. J. Non Cryst. Solids 2014, 401, 142-146. [CrossRef]

32. Zwanzig, R.; Mountain, R.D. High-Frequency Elastic Moduli of Simple Fluids. J. Chem. Phys. 1965, 43, 4464-4471. [CrossRef]

33. Fioretto, D.; Corezzi, S.; Caponi, S.; Scarponi, F.; Monaco, G.; Fontana, A.; Palmieri, L. Cauchy relation in relaxing liquids. J. Chem. Phys. 2008, 128, 214502. [CrossRef] [PubMed]

34. Kojima, S.; Kodama, M. Raman Scattering Study of Boson Peak in Cesium Borate Glass. Jpn. J. Appl. Phys. 1994, 33, 2886-2889. [CrossRef]

35. Kojima, S.; Kodama, M. Boson Peak in Modified Borate Glass. Phys. B 1999, 263-264, 336-338. [CrossRef]

36. Kojima, S.; Novikov, V.; Kodama, M. Fast relaxation, boson peak and anharmonicity in lithium borate glass. J. Chem. Phys. 2000, 113, 6344-6350. [CrossRef]

37. Kmitosos, E.I.; Krakassidesu, M.A.; Chryssikos, G.D. A vibrational study of lithium borate glasses with high $\mathrm{Li}_{2} \mathrm{O}$ content. Phys. Chem. Glass 1987, 28, 203-209. 
38. Simon, G.; Hehlen, B.; Courtens, E.; Longueteau, E.; Vacher, R. Hyper-Raman scattering analysis of the vibrations in vitreous boron oxide. Phys. Rev. B 2007, 76, 054210. [CrossRef]

39. Kojima, S.; Novikov, V.N.; Kofu, M.; Yamamuro, O. Neutron scattering studies of static and dynamic correlation lengths in alkali metal borate glasses. J. Non Cryst. Solids 2019, 518, 18-23. [CrossRef]

40. Carini, G., Jr.; Gilioli, E.; Tripodo, G.; Vasi, C. Structural changes and elastic characteristics of permanently densified vitreous $\mathrm{B}_{2} \mathrm{O}_{3}$. Phys. Rev. B 2011, 84, 024207. [CrossRef]

41. Kojima, S.; Kofu, M.; Yamamuro, O. Neutron scattering study of mixed alkali effect of borate glass. In Proceedings of the International Commission on Glass (ICG) Annual Meeting 2018, Yokohama, Japan, 23-26 September 2018. Abstract No. T15.

Publisher's Note: MDPI stays neutral with regard to jurisdictional claims in published maps and institutional affiliations.

(C) 2020 by the author. Licensee MDPI, Basel, Switzerland. This article is an open access article distributed under the terms and conditions of the Creative Commons Attribution (CC BY) license (http://creativecommons.org/licenses/by/4.0/). 